\title{
THE DIAGNOSTIC USE OF AN EAR OXIMETER IN CONGENITAL HEART DISEASE
}

\author{
BY \\ C. R. WOOLF, W. PAUL, AND R. W. GUNTON \\ From the Departments of Medicine and Pathological Chemistry, University of Toronto, and the Medical Service, \\ Toronto General Hospital, Toronto, Canada
}

Received July 19, 1957

The ear oximeter can serve two purposes in the investigation of congenital heart disease. It can provide a continuous record of arterial oxygen saturation and its changes in response to varying situations; it can inscribe a dye dilution curve of the central circulation following intravenous injection of the dye, Evans Blue (T-1824), from which the direction and magnitude of intra-cardiac shunts can be estimated. These two functions of the oximeter in the study of congenital heart disease have been described and developed by the Mayo Clinic group (Burchell and Wood, 1948; Nicholson et al., 1951; Swan et al., 1953; Broadbent and Wood, 1954); and by Gilmore et al. (1954).

The increase in cyanosis during exercise of patients with cyanotic congenital heart disease has long been observed clinically (Abbott, 1936) and more recently has been measured quantitatively as fall in arterial oxygen saturation by the oximeter (Montgomery et al., 1948; Ferguson et al., 1949a; Burchell et al., 1950; Van Lingen and Whidborne, 1952). This phenomenon is characteristic of patients with a central veno-arterial shunt, but does not distinguish them from patients with acquired heart disease or severe pulmonary disease, who may show a considerable fall of arterial oxygen saturation during exercise. Almost all previously reported studies have been carried out with the patient breathing room air; little attention has been paid to changes in arterial oxygen saturation when patients perform an exercise test while breathing 100 per cent oxygen (Ferguson et al., 1949b; Burchell et al., 1950).

It is the purpose of this paper to show that a decrease in arterial oxygen saturation during a standard exercise test while the subject is breathing pure oxygen occurs in the presence of a central veno-arterial shunt, but not in acquired heart disease or severe pulmonary disease. This test, used together with central dye dilution curves of Evans Blue has been found valuable in the routine investigation of congenital heart disease.

\section{METHOD}

The direct writing ear oximeter and its use in recording changes in arterial oxygen saturation have been described elsewhere (Paul, 1953, 1955; Woolf et al., 1956).

With the ear oximeter in place the patient was required to step up and down a 20-cm. step thirty times in one minute and then rested until the arterial oxygen saturation had returned to its usual level. He then breathed 99.8 per cent oxygen from a Boothby-type mask and when the arterial oxygen saturation had reached a steady state the exercise test was repeated.

After a period of rest in the supine position, dye injection was then made into an ante-cubital vein. A volume of $4 \mathrm{ml}$. of Evans' Blue dye solution $(20 \mathrm{mg}$.) was injected over a period of 1.5 to 2.0 seconds and was followed by $5.0 \mathrm{ml}$. of saline solution through the side-arm of a $\mathrm{Y}$ connection. The patient continued to breathe oxygen during inscription of the dye curve to prevent the minor fluctuations in arterial oxygen saturation encountered in patients breathing room air. In the interpretation of dye curves the principles outlined by Swan et al. (1953) and Broadbent and Wood (1954) have been followed. 
In the normal curve shown in Fig. 2A, dye, which has passed through the heart and lungs and out into systemic arteries, appears at the ear 11 seconds after the beginning of the injection. There is then a rapid upstroke to the peak concentration. The time from first appearance of dye to peak concentration has been designated "Build-up time" (BT) (Wood and Swan, 1954). Following the peak there is a rapid fall in dye concentration, forming a disappearance slope as the dye moves past the ear. This part of the curve never reaches the base line because it is interrupted by dye returning to the ear after a complete circulation to cause a second small peak concentration of recirculating dye. The disappearance slope of the primary curve may be extrapolated to intersect with the base line. The time from peak concentration to this intersect has been designated "Disappearance time" (DT).

In right-to-left shunt (Fig. 2B) some of the dye is carried with venous blood to the left side of the heart by-passing the lungs; this dye appears early at the ear, forming an initial peak concentration. Dye that has traversed the lungs produces a second peak concentration. This "double-hump" contour is characteristic of central veno-arterial shunt. Assuming complete mixing of dye with venous blood proximal to the shunt and utilizing the Hamilton principle that blood flow is proportional to the area of dilution curves of the central circulation, Swan et al. (1953) have calculated from dye curves the percentage of systemic venous blood which is shunted to the left side of the heart.

In left-to-right shunts (Fig. 2D) the appearance time and upstroke of the dye curve are normal. The peak concentration is lower than expected, but the characteristic features are the prolongation of the disappearance time, and absence of a clearly defined recirculation peak. In left-to-right shunts part of the dye that has traversed the lungs will pass into the systemic arteries, producing the initial normal part of the curve. The other part of the dye will pass through the shunt and through the lungs again. Part of this shunted dye that has passed through the shorter pulmonary circuit will appear earlier at the ear than the dye that returns from the systemic circulation. A succession of rapid recirculations accounts for the slow prolonged disappearance slope. The curve of left-to-right shunts may be distinguished from the curve of low cardiac output (Fig. 4C) by analysis of the ratio of disappearance time (DT) to build-up time (BT). BT is relatively short in left-to-right shunt, and prolonged in low cardiac output. DT/BT ratios greater than 2.0 suggest a left-to-right shunt (Broadbent and Wood, 1954).

\section{MATERIAL}

The patients were divided into 4 groups.

Group I (14 cases): Congenital heart disease with a right-to-left shunt.

Group II (12 cases): Non-cyanotic congenital heart disease.

Group III (10 cases): Acquired heart disease.

Group IV (20 cases): Pulmonary disease severe enough to cause a significant fall of the arterial oxygen saturation on exercise.

The age, sex, and diagnosis of all patients are shown in Tables I and II. The diagnosis was made by clinical and routine radiological examination. In addition, cardiac catheterization was carried out on all patients with congenital heart disease, selective angiocardiography on some, and the diagnosis was confirmed by the findings at operation in several of them. All patients in Group I were shown to have a right-to-left shunt by methods other than those under review in this study. Respiratory function tests were done on all patients with pulmonary disease (vital capacity, maximum breathing capacity, spirogram tracing; and in some cases residual volume and total lungcapacity).

\section{RESULTS}

These are summarized in Tables I and II.

Group I. All patients with a right-to-left intracardiac shunt showed a fall of the arterial oxygen saturation on exercise while breathing air and an equal or greater fall when the test was repeated while breathing oxygen (Fig. 1B). The normal response to exercise, breathing air, and breathing oxygen, is shown in Fig. 1A. In normal subjects there may be a small fall of arterial oxygen saturation on exercise breathing air (Woolf et al., 1956), but there is no fall when breathing oxygen.

The dye curves showed the characteristic short circulation time and double hump pattern (Fig. 2B). 
TABLE I

The Age, Sex, Diagnosis, Changes in Arterial Oxygen Saturation during Exercise, Breathing Air and OXygen, and Type of Dye Curve in Patients with Congenital Heart Disease

\begin{tabular}{|c|c|c|c|c|c|c|c|}
\hline & \multirow[t]{2}{*}{ Patient } & \multirow[t]{2}{*}{ Age } & \multirow[t]{2}{*}{ Sex } & \multirow[t]{2}{*}{ Diagnosis } & \multicolumn{2}{|c|}{$\begin{array}{l}\text { Decrease in per cent } \\
\text { oxygen saturation of } \\
\text { arterial blood during } \\
\text { exercise }\end{array}$} & \multirow[t]{2}{*}{$\begin{array}{l}\text { Dye } \\
\text { curve } \\
\text { type }\end{array}$} \\
\hline & & & & & $\begin{array}{l}\text { Breathing } \\
\text { air }\end{array}$ & \begin{tabular}{|} 
Breathing \\
$99 \cdot 8$ per \\
cent oxygen
\end{tabular} & \\
\hline $\begin{array}{l}\text { Group I } \\
R \rightarrow L \text { shunt }\end{array}$ & $\begin{array}{l}\text { R.L. } \\
\text { D.N. } \\
\text { N.C. } \\
\text { N.P. } \\
\text { N.F. } \\
\text { J.C. } \\
\text { M.T. } \\
\text { B.B. } \\
\text { I.N. } \\
\text { V.M. } \\
\text { J.B. } \\
\text { W.C. } \\
\text { C.L. } \\
\text { A.M. }\end{array}$ & $\begin{array}{l}15 \\
28 \\
27 \\
29 \\
\\
31 \\
16 \\
24 \\
25 \\
33 \\
28 \\
\\
28 \\
\\
21 \\
\\
\end{array}$ & $\begin{array}{l}M \\
M \\
F \\
F \\
F \\
F \\
F \\
F \\
F \\
F \\
F \\
F \\
F \\
F\end{array}$ & $\begin{array}{l}\text { Tetralogy of Fallot } \\
\text { Tetralogy of Fallot; lung cyst } \\
\text { Tetralogy of Fallot; kyphoscoliosis } \\
\text { Tetralogy of Fallot; after Brock opn. for pul- } \\
\text { monary stenosis } \\
\text { Atrial septal defect; pulmonary stenosis } \\
\text { Atrial septal defect; pulmonary stenosis } \\
\text { Atrial septal defect; pulmonary stenosis } \\
\text { Atrial septal defect; pulmonary hypertension } \\
\text { Atrial septal defect; pulmonary hypertension } \\
\text { Ventricular septal defect; pulmonary hyper- } \\
\text { tension } \\
\text { Ventricular septal defect; pulmonary hyper- } \\
\text { tension } \\
\text { Tricuspid atresia } \\
\text { Common truncus } \\
\text { Reversed shunt: ductus arteriosus }\end{array}$ & $\begin{array}{r}17 \cdot 5 \\
13 \cdot 3 \\
21 \cdot 2 \\
23 \cdot 7 \\
\\
8 \cdot 5 \\
9 \cdot 4 \\
11 \cdot 8 \\
11 \cdot 8 \\
13 \cdot 3 \\
21 \cdot 7 \\
18 \cdot 4 \\
8 \cdot 0 \\
24 \cdot 8 \\
7 \cdot 8\end{array}$ & $\begin{array}{r}18 \cdot 5 \\
21 \cdot 0 \\
33 \cdot 4 \\
23 \cdot 7 \\
9 \cdot 5 \\
9 \cdot 6 \\
9 \cdot 9 \\
12 \cdot 4 \\
14 \cdot 3 \\
22 \cdot 0 \\
18 \cdot 8 \\
9 \cdot 0 \\
39 \cdot 3 \\
2 \cdot 6\end{array}$ & $\begin{array}{c}\mathrm{R} \rightarrow \mathrm{L} \\
\mathrm{R} \rightarrow \mathrm{L} \\
\mathrm{R} \rightarrow \mathrm{L} \\
- \\
\mathrm{R} \rightarrow \mathrm{L} \\
\mathrm{R} \rightarrow \mathrm{L} \\
\mathrm{R} \rightarrow \mathrm{L} \\
\mathrm{R} \rightarrow \mathrm{L} \\
\mathrm{R} \rightarrow \mathrm{L} \\
\mathrm{R} \rightarrow \mathrm{L} \\
\mathrm{R} \rightarrow \mathrm{L} \\
\\
\text { Ab- } \\
\text { normal } \\
\mathrm{R} \rightarrow \mathrm{L} \\
\text { Normal }\end{array}$ \\
\hline $\begin{array}{l}\text { Group II } \\
\text { Non-cyanotic } \\
\text { congenital } \\
\text { heart disease }\end{array}$ & $\begin{array}{l}\text { I.W. } \\
\text { W.C. } \\
\text { A.D. } \\
\text { G.B. } \\
\text { D.C. } \\
\text { H.L. } \\
\text { I.M. } \\
\text { R.W. } \\
\text { M.E. } \\
\text { J.H. } \\
\text { M.L. } \\
\text { H.W. }\end{array}$ & $\begin{array}{l}54 \\
46 \\
26 \\
53 \\
27 \\
22 \\
28 \\
15 \\
32 \\
35 \\
42 \\
20\end{array}$ & $\begin{array}{l}F \\
M \\
F \\
F \\
F \\
M \\
F \\
M \\
F \\
M \\
F \\
M\end{array}$ & $\begin{array}{l}\text { Atrial septal defect } \\
\text { Atrial septal defect } \\
\text { Atrial septal defect } \\
\text { Atrial septal defect } \\
\text { Atrial septal defect } \\
\text { Ventricular septal defect } \\
\text { Pulmonary stenosis } \\
\text { Pulmonary stenosis } \\
\text { Patent ductus arteriosus } \\
\text { Patent ductus arteriosus } \\
\text { Patent ductus arteriosus } \\
\text { Patent ductus arteriosus }\end{array}$ & $\begin{array}{l}8 \cdot 1 \\
0 \\
2 \cdot 6 \\
1 \cdot 3 \\
0 \cdot 8 \\
1 \cdot 0 \\
0 \cdot 8 \\
1 \cdot 6 \\
2 \cdot 2 \\
2 \cdot 2 \\
0 \\
2 \cdot 6\end{array}$ & $\begin{array}{l}0 \\
0 \\
0 \\
0 \\
0 \\
0 \\
0 \\
0 \\
0 \\
0 \\
0 \\
0\end{array}$ & $\begin{array}{l}\mathrm{L} \rightarrow \mathrm{R} \\
\mathrm{L} \rightarrow \mathrm{R} \\
\mathrm{L} \rightarrow \mathrm{R} \\
\mathrm{L} \rightarrow \mathrm{R} \\
\mathrm{L} \rightarrow \mathrm{R} \\
\mathrm{L} \rightarrow \mathrm{R} \\
\text { Normal } \\
\text { Normal } \\
\mathrm{L} \rightarrow \mathrm{R} \\
\mathrm{L} \rightarrow \mathrm{R} \\
\text { Normal } \\
\text { ? Nor- } \\
\text { mal }\end{array}$ \\
\hline
\end{tabular}

In one patient (A.M.) with patent ductus arteriosus, pulmonary hypertension and reversal of shunt, there was only a slight fall of the arterial oxygen saturation on exercise, breathing oxygen, even with the oximeter on the left ear (Fig. 3B). This was due to the sampling site, the ear supplied by the left carotid artery, being proximal to the site of the veno-arterial shunt. The dye curve was normal in form (Fig. 4B).

Group II. The patients with acyanotic congenital heart disease showed varying degrees of arterial oxygen desaturation on exercise, breathing air, and no fall on exercise, breathing oxygen (Fig. 1D and 3A).

The dye curves showed the pattern of left-to-right shunt in the patients with atrial septal defect (Fig. 2D) and ventricular septal defect, and in two of those with patent ductus arteriosus. The dye curves were normal in pulmonary stenosis and in the other two cases of patent ductus arteriosus (Fig. 4A).

Group III. Patients with acquired heart disease showed a variable fall of the arterial oxygen saturation on exercise, breathing air, and there was no fall of the arterial oxygen saturation on exercise breathing oxygen (Fig. 3C). 
The dye curves showed a prolonged circulation time in the presence of heart failure and the contour of a low cardiac output (Fig. 4C).

Group $I V$. The patients with pulmonary disease all showed a significant fall of arterial oxygen saturation on exercise breathing air, but in only one case was there a fall on exercise breathing oxygen, and this fall was barely measurable. In some patients there was mainly a ventilatory defect (J.F., Fig. 5C), in others mainly a diffusion defect (J.I., Fig. 5B), and in others a combination of factors (Fig. 5A).

TABLE II

The Age, Sex, Diagnosis, and Changes in Arterial Oxygen Saturation during Exercise, Breathing Air and Oxygen, of Patients with Acquired Heart Disease and Pulmonary Disease

\begin{tabular}{|c|c|c|c|c|c|c|}
\hline & \multirow[t]{2}{*}{ Patient } & \multirow[t]{2}{*}{ Age } & \multirow[t]{2}{*}{$\operatorname{Sex}$} & \multirow[t]{2}{*}{ Diagnosis } & \multicolumn{2}{|c|}{$\begin{array}{c}\text { Decrease in per cent oxygen } \\
\text { saturation of arterial blood } \\
\text { during exercise }\end{array}$} \\
\hline & & & & & Breathing air & $\begin{array}{c}\text { Breathing } \\
99 \cdot 8 \text { per cent } \\
\text { oxygen }\end{array}$ \\
\hline $\begin{array}{l}\text { Group III } \\
\text { Acquired } \\
\text { heart disease }\end{array}$ & $\begin{array}{l}\text { F.D. } \\
\text { H.B. } \\
\text { C.S. } \\
\text { G.L. } \\
\text { F.G. } \\
\text { V.C. } \\
\text { R.S. } \\
\text { M.S. } \\
\text { V.E. } \\
\text { D.V. }\end{array}$ & $\begin{array}{l}28 \\
36 \\
48 \\
47 \\
21 \\
35 \\
15 \\
64 \\
26 \\
33\end{array}$ & $\begin{array}{l}\mathbf{F} \\
\mathbf{F} \\
\mathbf{M} \\
\mathbf{M} \\
\mathbf{F} \\
\mathbf{F} \\
\mathbf{M} \\
\mathbf{M} \\
\mathbf{M} \\
\mathbf{M}\end{array}$ & $\begin{array}{l}\text { Mitral stenosis } \\
\text { Mitral stenosis } \\
\text { Mitral stenosis } \\
\text { Mitral stenosis } \\
\text { Mitral and aortic stenosis, and regurgitation } \\
\text { Mitral and aortic stenosis, and regurgitation } \\
\text { Aortic regurgitation } \\
\text { Aortic regurgitation } \\
\text { Primary pulmonary hypertension } \\
\text { Constrictive pericarditis }\end{array}$ & $\begin{array}{l}1 \cdot 8 \\
2 \cdot 0 \\
0 \cdot 7 \\
0 \cdot 5 \\
1 \cdot 0 \\
0 \\
0 \\
0 \\
2 \cdot 8 \\
5 \cdot 4\end{array}$ & $\begin{array}{l}0 \\
0 \\
0 \\
0 \\
0 \\
0 \\
0 \\
0 \\
0\end{array}$ \\
\hline $\begin{array}{l}\text { Group IV } \\
\text { Pulmonary } \\
\text { disease }\end{array}$ & $\begin{array}{l}\text { J.F. } \\
\text { M.R. } \\
\text { R.H. } \\
\text { B.W. } \\
\text { C.G. } \\
\text { G.W. } \\
\text { W.K. } \\
\text { K.H. } \\
\text { L.J. } \\
\text { W.E. } \\
\text { J.W. } \\
\text { K.S. } \\
\text { H.H. } \\
\text { J.Bl. } \\
\text { G.C. } \\
\text { J.I. } \\
\text { M.B. } \\
\text { G.M. } \\
\text { G.G. } \\
\text { P.D. }\end{array}$ & $\begin{array}{l}19 \\
42 \\
46 \\
54 \\
63 \\
55 \\
60 \\
49 \\
55 \\
61 \\
68 \\
45 \\
53 \\
34 \\
32 \\
27 \\
37 \\
39 \\
33 \\
38\end{array}$ & $\begin{array}{l}\mathbf{F} \\
\mathbf{F} \\
\mathbf{M} \\
\mathbf{M} \\
\mathbf{M} \\
\mathbf{M} \\
\mathbf{M} \\
\mathbf{M} \\
\mathbf{M} \\
\mathbf{M} \\
\mathbf{M} \\
\mathbf{M} \\
\mathbf{M} \\
\mathbf{M} \\
\mathbf{M} \\
\mathbf{M} \\
\mathbf{M} \\
\mathbf{F} \\
\mathbf{F}\end{array}$ & $\begin{array}{l}\text { Kyphoscoliosis } \\
\text { Inactive tuberculosis; thoracoplasty } \\
\text { Emphysema } \\
\text { Emphysema } \\
\text { Emphysema } \\
\text { Emphysema } \\
\text { Emphysema } \\
\text { Emphysema } \\
\text { Emphysema; asthma } \\
\text { Emphysema; asthma } \\
\text { Emphysema; pulmonary fibrosis } \\
\text { Emphysema; pulmonary fibrosis } \\
\text { Emphysema; pulmonary fibrosis } \\
\text { Pulmonary fibrosis } \\
\text { Pulmonary fibrosis } \\
\text { Berylliosis } \\
\text { ? Sarcoidosis } \\
\text { ? Sarcoidosis } \\
\text { Secondary carcinoma } \\
\text { Secondary carcinoma }\end{array}$ & $\begin{array}{r}8 \cdot 0 \\
11 \cdot 2 \\
6 \cdot 3 \\
5 \cdot 8 \\
14 \cdot 7 \\
6 \cdot 2 \\
7 \cdot 3 \\
6 \cdot 7 \\
10 \cdot 3 \\
14 \cdot 7 \\
16 \cdot 5 \\
8 \cdot 9 \\
6 \cdot 5 \\
13 \cdot 1 \\
10 \cdot 5 \\
12 \cdot 6 \\
17 \cdot 4 \\
7 \cdot 5 \\
4 \cdot 3 \\
5 \cdot 8\end{array}$ & $\begin{array}{l}0 \\
0 \\
9 \\
0 \\
0 \\
0 \cdot 7 \\
0 \\
0 \\
0 \\
0 \\
0 \\
0 \\
0 \\
0 \\
0 \\
0 \\
0 \\
0 \\
0 \\
0\end{array}$ \\
\hline
\end{tabular}

\section{DisCUSSION}

Two reasons have been proposed to explain the decrease in arterial oxygen saturation on exercise in patients with a central veno-arterial shunt. On exercise, the blood returning to the right atrium (from active muscles) will have a lower oxygen content than in the resting state. Some of this blood will pass through the cardiac defect to the left side of the heart and reduce the arterial oxygen saturation. This could occur without any change in blood flow through the shunt (Burchell and Wood, 1948). A second explanation is that the proportion of venous blood shunted does in fact increase with exertion (Bing et al., 1947; Hickam, 1949; Burchell et al., 1950). 


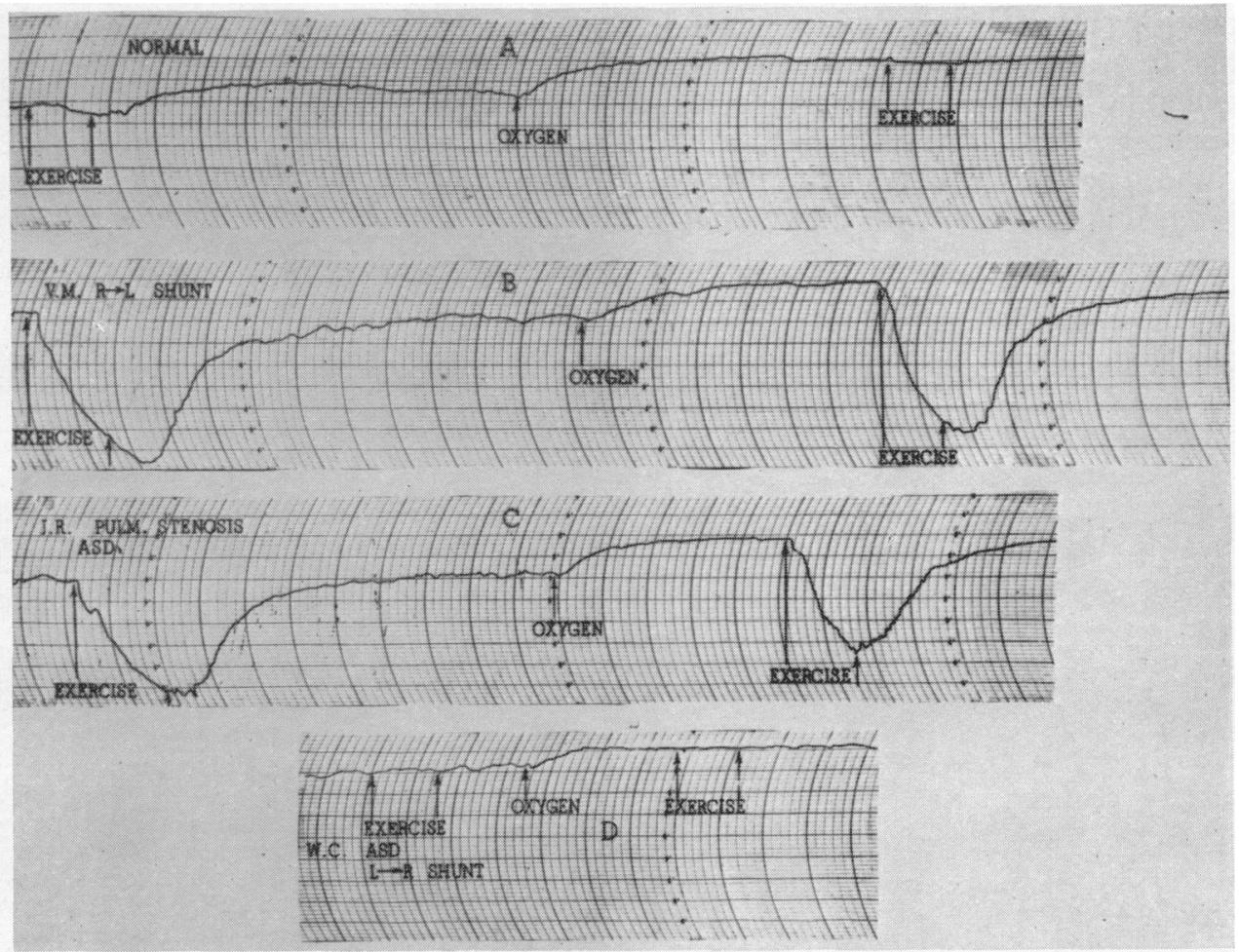

FIG. 1.-Changes in arterial oxygen saturation during exercise, breathing air and then breathing oxygen. To be read from left to right. A downward deflection of the record indicates a fall of arterial oxygen saturation, an upward deflection a rise. (A) Normal subject: slight fall on exercise when breathing air, but no fall when breathing oxygen. (B) Right-to-left shunt (ventricular septal defect and pulmonary hypertension): severe fall of arterial oxygen saturation on exercise when breathing air and when breathing oxygen. (C) Right-to-left shunt (atrial septal defect and pulmonary stenosis): this patient had a normal arterial oxygen saturation at rest. (D) Left-toright shunt (atrial septal defect): no fall of arterial oxygen saturation during exercise breathing air or oxygen.

When the subject breathes pure oxygen, the shunted venous blood is not exposed to the increased oxygen tension in the pulmonary alveoli. The fall in arterial oxygen saturation should be as great as that produced by identical exercise when breathing air. This has been true in all the patients reported in this study. In three there was an even greater fall during exercise when breathing pure oxygen than during exercise breathing room air. The reason for this is not clear. It is possible that the general rise in arterial oxygen saturation at the start of oxygen breathing before exercise improved the patient subjectively so that he performed the test with more vigour, exaggerating the mechanisms producing the fall.

The absence of a fall in arterial oxygen saturation during exercise breathing pure oxygen served to distinguish the patients with a left-to-right shunt, acquired heart disease, and severe pulmonary disease from those with a right-to-left shunt. In the former group almost all the blood from the right side of the heart passes through lung tissue. The increase in alveolar oxygen tension, when pure oxygen is breathed, compensates for defects of circulation, diffusion, and ventilation.

In one patient with severe pulmonary emphysema (G.W., Table II), a slight fall of arterial oxygen saturation of 0.7 per cent was observed during exercise breathing oxygen. Using the criteria adopted from this study, a small central veno-arterial shunt was indicated by this observation. A true but minor shunt may have occurred from an unsealed foramen ovale associated with 
pulmonary hypertension; or multiple small intra-pulmonary veno-arterial shunts, as described by Riley and Cournand (1949) in pulmonary disease, may have been demonstrated.

It would be expected that a patient with pulmonary arterio-venous aneurysm would show the same response as a patient with right-to-left intra-cardiac shunt. However, Hultgren and Gerbode (1954) have reported one case where there was no significant fall of arterial oxygen saturation on exercise while breathing air, and there was evidence that during exercise the flow through the fistula decreased while the flow through the pulmonary capillary bed increased.

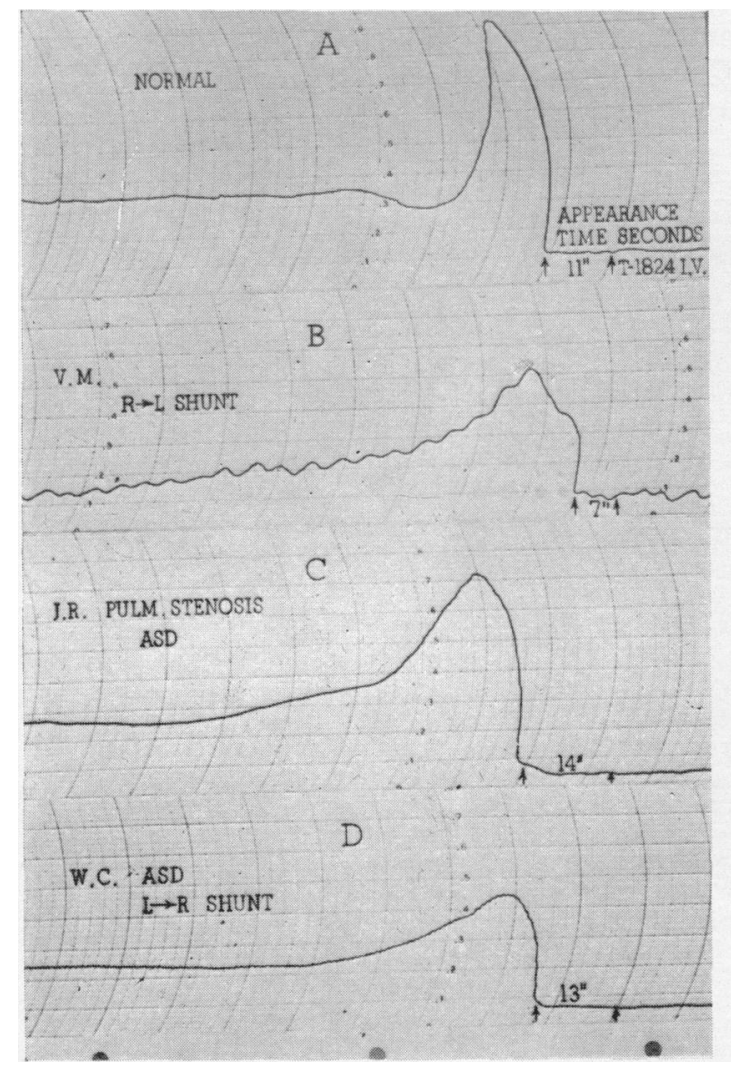

FIG. 2.-Evans' Blue dye curves of same patients as in Fig. 1. To be read from right to left. First arrow marks time of injection of Evans' Blue dye into arm vein. Patients at rest breathing pure oxygen. (A) Normal subject: rapid upstroke to the peak concentration followed by a rapid fall in dye concentration and then second small recirculation peak. (B) Right-to-left shunt: short appearance time, and double hump pattern as part of dye passes across ventricular septal defect and reaches ear sooner than dye that passes through pulmonary circulation. (C) Right-to-left shunt: just before the main upward deflection there is a slight rise due to a small right-to-left shunt at rest. There is some prolongation of the descent of the curve suggesting left-to-right shunt. Importance of $R \rightarrow L$ shunt in this case was shown by exercise test (Fig. 1). (D) Left-to-right shunt: normal appearance time and normal upstroke to low peak concentration. The descent of the curve is prolonged and there is no clearly defined late recirculation peak as in the normal (see text).

It is possible that very small right-to-left shunts may not be demonstrated by the exercise test performed during pure oxygen breathing. When a subject breathes 99.8 per cent oxygen from a mask, the amount of oxygen dissolved in physical solution in the plasma may be as great as $2.2 \mathrm{ml}$. per $100 \mathrm{ml}$. (Wood, 1949) and may be sufficient to saturate fully the hæmoglobin of small amounts of venous blood entering the left side of the heart through a septal defect. Suspicion that small right-to-left shunts may be missed by the exercise test performed during oxygen breathing is thus far speculative and based on failure to show arterial oxygen desaturation in five cases of uncomplicated atrial septal defect (Table I, Group II, Fig. 1D). Although in this condition the shunt is commonly considered to be entirely left to right, Hickam (1949), and Calazel et al. (1951) had reported that small right-to-left shunts may occur, and Swan et al. (1954) found small right-to-left shunts in three of five cases of uncomplicated atrial septal defect by injection of dye into the venæ cavæ. In the present study a right-to-left shunt was clearly demonstrated by the performance of exercise, while breathing pure oxygen, in five cases of atrial septal defect complicated by pulmonary stenosis or pulmonary hypertension (Table I, Group I, Fig. 1C). The test has been sensitive enough to detect a right-to-left shunt through a patent foramen ovale barely large enough to admit a small 
dissecting probe, in a patient shown at necropsy to have pulmonary stenosis and an intact ventricular septum (Example 4).

The dye curves have shown characteristic early appearance time and "double hump" pattern in patients with large right-to-left shunts (Fig. 2B; Fig. 6), and smaller early deflections above the base line (Fig. 2C) in patients with small right-to-left shunts who did not have cyanosis or significant arterial oxygen unsaturation at rest. The characteristic early recirculation and gradual downstroke of a left-to-right shunt has always been found in patients with proven atrial and ventricular septal defect, but has not been as decisive in patent ductus arteriosus. Recirculation occurs later in patency of the ductus than in either septal defect and more nearly simulates the normal curve. Reversal of flow in patent ductus arteriosus cannot be demonstrated well by either dye curve or exercise test, because, even if the left ear is used, the left common carotid artery which supplies it is proximal to the usual site of entrance of the ductus into the aorta.

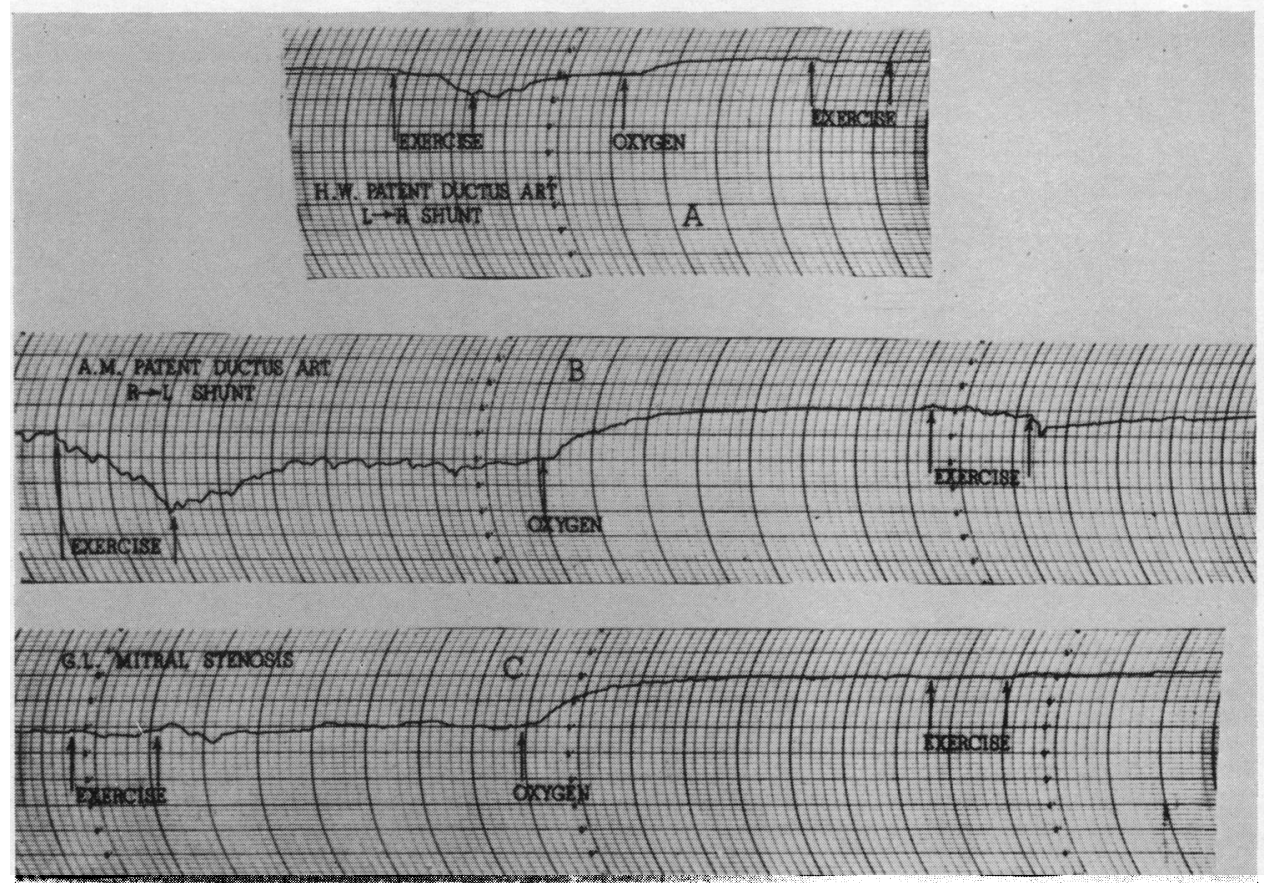

FIG. 3.-Changes in arterial oxygen saturation during exercise, first breathing air and then breathing oxygen. (A) Patent ductus arteriosus: note slight fall of arterial oxygen saturation when breathing air and no fall when breathing oxygen. A normal response not indicative of right-to-left shunt. (B) Patent ductus arteriosus with pulmonary hypertension and reversal of shunt: note fall of arterial oxygen saturation on exercise breathing air and a smaller fall when breathing oxygen. Indicates $R \rightarrow L$ shunt (see text). (C) Mitral stenosis: note slight fall of arterial oxygen saturation breathing air; no fall breathing oxygen; not indicative of $R \rightarrow L$ shunt.

Three stages in the progression of atrial septal defect are demonstrated by dye curves in Fig. 6 . The characteristic early recirculation and gradual downstroke of a left-to-right shunt is present in uncomplicated cases. Pulmonary hypertension will cause first a bi-directional shunt and later, when right ventricular failure occurs, a more complete right-to-left shunt with obvious cyanosis and clubbing.

The oximeter tests described in this study are safe and simple to perform; they cause little discomfort and may be completed within thirty minutes. In cases where the clinical diagnosis is readily apparent and where cardiac catheterization is indicated to obtain quantitative information, their 
value is supplementary. They can, however, serve two important purposes. First, they may be used as screening tests in patients suspected of having congenital heart disease, where cardiac catheterization would not normally be carried out because of absence of symptoms or doubtful clinical evidence of heart disease. Second, the oximeter tests may help the solution of difficult cases, even where a full cardiac investigation has been completed.

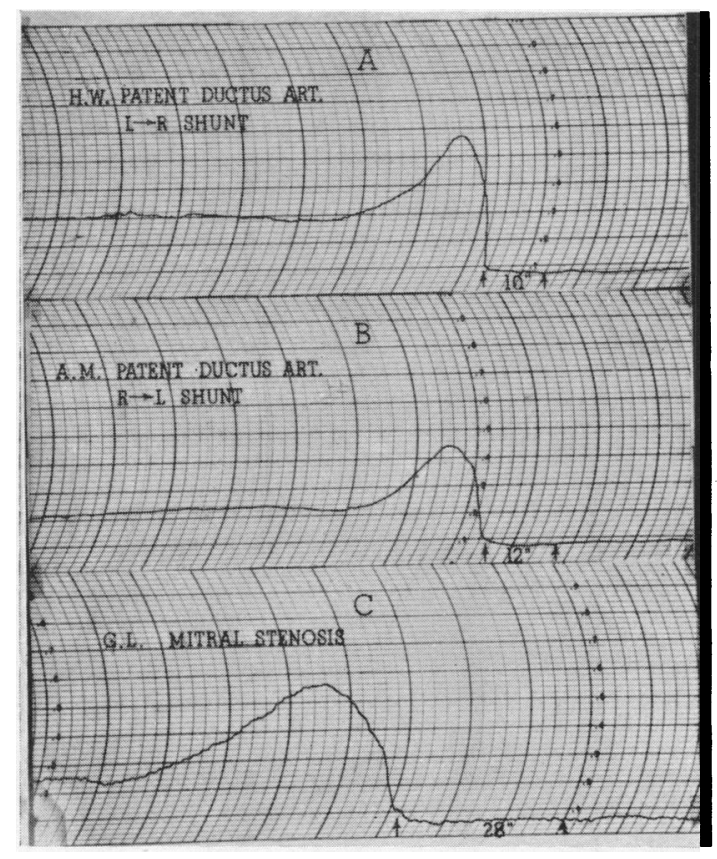

FIG. 4.-Evans' Blue dye curves of same patients as in Fig. 3. (A) and (B): Comparatively normal dye curves of patients with patent ductus arteriosus, irrespective of direction of the shunt (see text). (C) Mitral stenosis: Note prolongation of appearance time and slow ascent and slow descent of the curve, characteristic of low cardiac output.

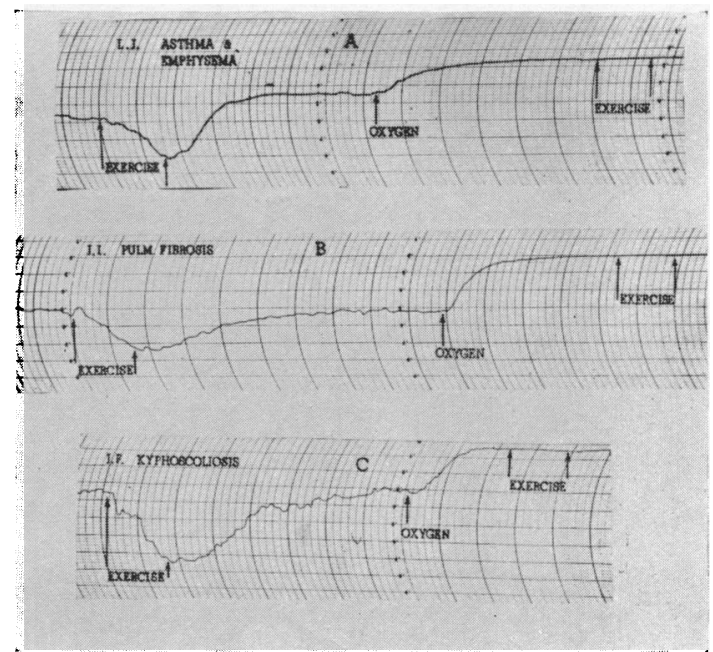

FIG. 5.-Changes in arterial oxygen saturation during exercise, first breathing air and then breathing oxygen, in patients with pulmonary disease. Note all have the same characteristics of a fall of arterial oxygen saturation, breathing air, and no fall of arterial oxygen saturation when breathing oxygen.

Examples. (1) When there is both a congenital heart lesion and a respiratory disability it is possible to decide whether the fall of arterial oxygen saturation during exercise, breathing air, is due to pulmonary insufficiency or to a veno-arterial shunt.

N.C., a 27-year-old housewife, had both a severe kyphoscoliosis and congenital heart disease. There was a severe fall of the arterial oxygen saturation on exertion breathing air. The presence of an even greater fall when breathing oxygen confirmed the clinical impression that the cyanosis was primarily due to a right-to-left shunt. The dye curve showed that a right-to-left shunt was present also at rest.

(2) To demonstrate the presence of bi-directional shunts.

J.R., a 27-year-old salesman, showed the clinical signs of pulmonary stenosis. At rest the arterial oxygen saturation was normal. The dye curve (Fig. 2C) showed a normal appearance time but a very small rise just before the main upward deflection. This suggested the possibility of a small right-to-left shunt at rest. There was slight prolongation of the descent of the curve, suggesting some left-to-right shunt. On exercise breathing air (Fig. 1C) there was a fall of arterial oxygen saturation of $24 \cdot 1$ per cent and when breathing oxygen a fall of 23.7 per cent. This clearly 
illustrated that there was a considerable shunt of blood from right to left on exercise, probably through a septal defect.

(3) To distinguish acquired heart disease from congenital heart disease.

H.B., a 36-year-old housewife in congestive heart failure, was thought to have mitral stenosis, but the auscultatory, radiographic, and phonocardiographic evidence was indecisive. Right heart catheterization showed no left-to-right shunt, pulmonary artery pressure $75 / 40 \mathrm{~mm}$. $\mathrm{Hg}$, and wedge pressure $15 \mathrm{~mm}$. Hg. Arterial oxygen saturation was 90 per cent, but she appeared clinically deeply cyanosed. There was indecision about valvotomy. Congenital heart disease (atrial septal defect) with R. $\rightarrow$ L. shunt was suspected. Dye curve and exercise test showed no R. $\rightarrow$ L. shunt. At operation tight mitral stenosis was demonstrated.

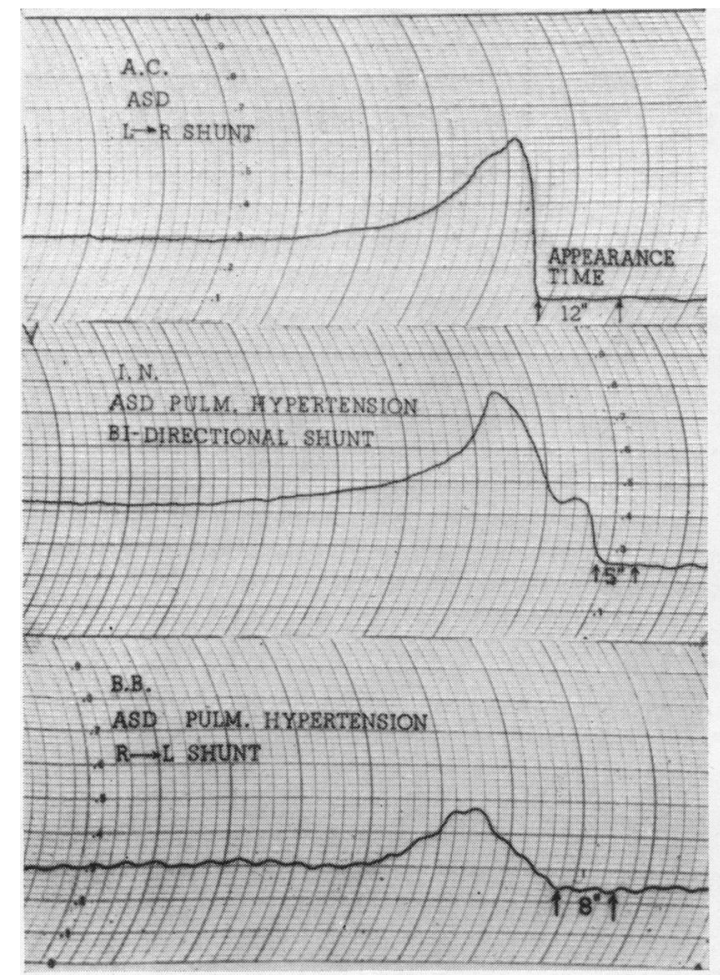

FIG. 6.-Dye curves in three patients with atrial septal defect. To be read from right to left. Top panel (A.C.) Characteristic $L \rightarrow R$ shunt pattern: normal appearance time, normal upstroke, early re-circulation, gradual downstroke. Middle panel (I.N.). Bi-directional shunt. Early appearance, distinct early circulation produced by part of dye passing direct from right atrium to left, gradual downstroke of $L \rightarrow R$ shunt. Lower panel (B.B.). Early appearance and double hump pattern of large $R \rightarrow L$ shunt. Oscillations in tracing are always found in pure $\mathbf{R} \rightarrow$ L shunt, even with patient breathing pure oxygen and may represent respiratory variations in shunt.

(4) To aid in the selection of surgical treatment.

D.N., a 27-year-old housewife, had clinical evidence of infundibular pulmonary stenosis, confirmed by angiocardiography, which also demonstrated a right aortic arch, but showed no early appearance of dye in aorta. Cyanosis and clubbing were questionable; arterial oxygen saturation at rest was 91 per cent. The right ventricle could not be entered at cardiac catheterization and the pressure in that chamber was unknown. In the discussion of surgical treatment it was put forward that the patient had several features of Fallot's tetralogy, but probably had ventricular septal defect with equal pressure in the two ventricles, without over-riding aorta. It was feared that infundibular resection alone (Brock) might create a left-to-right shunt through the ventricular septal defect and would be less desirable than an open heart procedure, which would allow the septal defect to be repaired. Dye curve and exercise tests demonstrated clearly a R. $\rightarrow$ L. shunt, but so small as to be hæmodynamically unimportant. The Brock operation was carried out but the patient did not survive. Post-mortem the ventricular septum was intact. An unsealed foramen ovale would just admit a small dissecting probe. 


\section{SUMMARY}

In the investigation of congenital heart disease an ear oximeter has been use to provide a continuous record of arterial oxygen saturation during exercise, with the patient first breathing air and then breathing pure oxygen. Dye dilution curves of the central circulation following intravenous injection of Evans' Blue dye have been recorded.

In the presence of a right-to-left shunt at rest the dye curves showed a short appearance time and a characteristic double hump form. With exercise there was a fall of the arterial oxygen saturation when breathing air and when breathing oxygen.

In the presence of a left-to-right shunt the dye curves showed a normal appearance time, a normal steep ascent, but prolongation of the descent and absence of a recirculation peak. With exercise there was a varying degree of fall of the arterial oxygen saturation while breathing air, but no fall when breathing oxygen.

In pulmonary disease severe enough to cause a significant fall of the arterial oxygen saturation during exercise while breathing air, there was no fall during exercise while breathing oxygen.

The oximeter tests have been valuable in detecting intra-cardiac shunts, in particular right-toleft shunt in the presence of a normal arterial oxygen saturation at rest. They have distinguished the cyanosis of right-to-left shunt from the cyanosis of pulmonary disease and acquired heart disease.

The authors wish to acknowledge the technical assistance of Miss Sylvia Davies and Mr. T. Nelberg and the financial support of the Ontario Heart Foundation. The use of the oximeter was made possible by the financial support of the Atkinson Charitable Foundation.

\section{ADDENDUM}

A 42-year-old woman with an arteriovenous aneurysm of the upper lobe of the right lung (proved by angiopneumogram and operation) showed a fall of arterial oxygen saturation of 7 per cent on exercise while breathing air and a fall of 7 per cent whilst breathing oxygen.

\section{REFERENCES}

Abbott, M. E. (1936). Atlas of Congenital Cardiac Disease. American Heart Association, New York.

Bing, R. J., (1951). Bull. Johns Hopkins Hosp., 88, 20.

- Vandan, L. D., and Gray, F. D. (1947). Bull. Johns Hopkins Hosp., 80, 121.

Broadbent, J. C., and Wood, E. H. (1954). Circulation, 9, 890.

Burchell, H. B., and Wood, E. H. (1948). Mod. Concepts Cardiovas. Disease, 17, 25.

, Taylor, B. E., Knutson, J. R. B., and Wood, E. H. (1950). Circulation, 1, 404.

Calazel, P., Gerard, R., Daley, R., Draper, A., Foster, J., and Bing, R. J. (1951). Bull. Johns Hopkins Hosp., 88, 20. Ferguson, J. K. W., Finlayson, D. M., and Hilliard, I. M. (1949a). Federation Proc., 8, 44.

,$--(1949 b)$. Unpublished observations.

Gilmore, H. R., Hamilton, M., Kopelman, H., and Sommer, L. S. (1954). Brit. Heart J., $16,301$.

Hickam, J. B. (1949). Amer. Heart J., 38, 801.

Hultgren, H. N., and Gerbode, F. (1954). Amer. J. Med., 17, 126.

Montgomery, G. E., Jr., Wood, E. H., Burchell, H. B., Dry, T. J., Parker, R. W., and Helmholz, H. F. (1948). Amer. Heart J., 36, 668.

Nicholson, J. W., III, Burchell, H. B., and Wood, E. H. (1951). J. Lab. clin. Med., 37, 353.

Paul, W. (1953). J. Scientific Instruments, 30, 165.

(1955). J. Scientific Instruments, 32, 286.

Riley, R. L., and Cournand, A. (1949). J. App. Physiol., 1, 825.

Swan, H. J. C., Burchell, H. B., and Wood, E. H. (1954). Circulation, 10, 705.

-, Zapata Diaz, J., and Wood, E. H. (1953). Circulation, 8, 70.

Van Lingen, B., and Whidborne, J. (1952). Circulation, 6, 740.

Wood, E. H. (1949). J. App. Physiol., 1, 567.

-, and Swan, H. J. C. (1954). J. App. Physiol., 6, 797.

Woolf, C. R., Gunton, R. W., and Paul, W. (1956). Amer. Rev. Tuberc., 74, 511. 